\title{
PELAKSANAAN PENGAWASAN FUNGSIONAL MENUJU OPTIMALISASI KINERJA INSPEKTORAT PROVINSI NUSA TENGGARA TIMUR
}

\author{
Matius Ngadi Oli \\ Mahasiswa Program Pasca Sarjana Program Studi Ilmu Hukum Universitas Nusa \\ Cendana, Kupang, Nusa Tenggara Timur \\ Korespondensi: nmatius58@yahoo.com
}

\begin{abstract}
Abstrak
Penelitian ini membahas tentang pelaksanaan pengawasan fungsional dalam rangka optimalisasi kinerja di Inspektorat Provinsi NTT serta tindak lanjut dari hasil pengawasan fungsional tersebut sepanjang tahun 2010-2012. Inspektorat Provinsi NTT sebagai subsistem pemerintahan mempunyai andil besar dalam terselenggaranya kepemerintahan yang baik dan bebas dari praktik Korupsi, Kolusi dan Nepotisme (Good Governance and Clean Governance). Inspektorat Provinsi NTT sebagai aparat pengawasan fungsional dalam melaksanakan fungsi pengawasan internal pemerintah telah mampu merespon secara signifikan berbagai macam permasalahan dan perubahan yang terjadi, baik politik, ekonomi maupun sosial melalui suatu program dan kegiatan yang ditetapkan dalam suatu kebijakan pengawasan yang menyeluruh.
\end{abstract}

Kata-kata Kunci: Implementasi; Pengawasan; Optimalisasi Kinerja.

\begin{abstract}
Supervision has an important role to undergo many planned programs well. Supervision is consisted of three steps which are standard determination, measurement of resulted standard, and necessary correction of supervision result. This article talks about a functional supervision implementation to optimalize work of Nusa Tenggara Timur Inspectorat and its supervision follow-up. According to research and analysis results that have been conducted, they show that Nusa Tenggara Timur Inspectorat, as a functional supervision apparatus which supervises government internally, has responsed to various problems and changes significantly through programs and events on comprehensive supervision policy.
\end{abstract}

Key Words: Implementation; Supervision; Work Optimization. 


\section{PENDAHULUAN}

Pengawasan erat sekali kaitannya dengan perencanaan. Pengawasan hanya akan berjalan kalau ada rencana program/kegiatan untuk diawasi. Rencana digunakan sebagai standar untuk mengawasi karena program/ kegiatan harus dijalankan sesuai rencana. Pada umumnya pengawasan terdiri dari 3 (tiga) langkah yaitu: menentukan standar, mengukur hasil atas dasar standar dan mengambil tindakan perbaikan yang diperlukan. ${ }^{1}$

Standar pengukuran yang dipakai biasanya sudah ditentukan oleh penanggung jawab program/kegiatan, di mana pengawas selanjutnya mengukur hasil-hasilnya dengan mengacu kepada standar tersebut. Hasil pengukurannya sebagai dasar untuk menyimpulkan apakah pelaksanaan kegiatan telah diselenggarakan secara efisien, efektif, ekonomis dan tertib aturan. Pengawasan akan sia-sia tanpa tindakan perbaikan, apabila dalam pengukuran hasil ditemukan keadaan tidak sesuai standar yang direncanakan, maka pengawas harus menganjurkan tindakan perbaikan.

Hal yang utama dari pengawasan oleh APIP (Aparat Pengawas Internal Pemerintah) adalah pemeriksaan (auditing), pemantauan (monitoring), evaluasi, review, sosialisasi dan asistensi, yang semuanya lebih ditekankan pada upaya preventif atas penyimpangan yang mengarah kepada mis-manajemen yang berdampak kepada ketidaktertiban administrasi maupun tindakan korupsi. Tindakan kuratif merupakan pilihan terakhir manakala sudah terjadi penyimpangan yang mengarah pada tindak pidana korupsi.

Pelaksanaan penanganan tindak lanjut hasil pengawasan tidak selalu berjalan lancar, seperti yang terjadi pada rekomendasi hasil pengawasan Inspektorat Provinsi Nusa Tenggara Timur yang belum dapat ditindaklanjuti. Hasil pemutakhiran data hasil pemeriksaan per 31 Desember 2012 pada Inspektorat Provinsi NTT masih tersisa tunggakan kerugian daerah senilai Rp 10.385.298.017,00 yang belum dapat ditindaklanjuti, dan terdapat 356 rekomendasi dari laporan hasil pemeriksaan Inspektorat Provinsi NTT sejak tahun 2002 yang belum selesai tindak lanjutnya. Sulitnya menangani tindak lanjut hasil pengawasan fungsional tersebut, antara lain: pihak ketiga/rekanan sudah pindah alamat dan/atau pailit, pimpinan instansi sudah pindah/mutasi dan dokumen hilang, adanya sanggahan yang terlambat, pegawai yang terkait sudah meninggal serta hasil pengawasan kurang jelas. Selama ini penanganan tindak lanjut hasil pengawasan umumnya terkait dengan temuan keuangan, sehingga temuan yang terkait dengan kegiatan teknis dan administratif kurang mendapat penekanan. Jenis temuan teknis dan administratif tidak dapat diabaikan begitu saja, karena kedua jenis temuan tersebut dapat menjadi penyebab terjadinya kerugian negara dan daerah. 
Selain melaksanakan pengawasan, Inspektorat Provinsi NTT juga melaksanakan tugas tambahan menyelenggarakan monitoring atau pemantauan. Pemantauan tersebut dilaksanakan secara berkesinambungan sejak tahap perencanaan sebagai salah satu bentuk pengarahan dan penjagaan terhadap pelaksanaan tugas dan fungsi instansi pemerintah, tahap pelaksanaan (on going) dan pasca program/kegiatan sebagai salah satu bentuk pengarahan dan penjagaan terhadap pelaksanaan tugas pokok dan fungsi instansi pemerintah agar dalam implementasinya tetap sesuai dengan kebijakan, rencana, prosedur dan ketentuan perundang-undangan yang berlaku. $^{2}$

Bahwasanya realitas menunjukkan adanya kompleksitas problematika pelaksanaan tugas umum pemerintahan dan tugas pembangunan melalui program/kegiatan, bidang pengawasan memegang fungsi strategis untuk pengamanannya menuju tujuan program/kegiatan Pemerintah Provinsi NTT. Berkaitan dengan itu, penelitian mengenai kinerja pengawasan sangat relevan dilakukan sebagai masukan bagi pimpinan unit kerja untuk perbaikan manajemen. Sejalan dengan itu permasalahan yang hendak dibahas di sini adalah: Bagaimana pelaksanaan pengawasan fungsional dalam rangka optimalisasi kinerja di Inspektorat Provinsi NTT serta tindak lanjut dari hasil pengawasan fungsional tersebut sepanjang tahun 2010-2012.

\section{PEMBAHASAN}

\section{Pelaksanaan Pengawasan Fungsional Terhadap Optimalisasi Kinerja Inspektorat Provinsi NTT}

Inspektorat Provinsi NTT sebagai sub-sistem Pemerintahan Provinsi mempunyai andil besar atas terselenggaranya kepemerintahan yang baik. Melalui pelaksanaan tugas dan fungsi auditor yang akuntabel maka akan terkendali pelaksanaan tugas unitunit kerja lingkup Pemerintahan Provinsi NTT dalam mencapai tujuannya, serta cara mencapai tujuan tersebut yang dilakukan secara efisien dan efektif sesuai dengan peraturan yang berlaku.

Pemerintahan Provinsi NTT berkepentingan untuk terwujudnya sistem pengawasan yang memadai guna menjamin tercapainya tujuan dan pelaksanaan kegiatan secara efektif, efisien dan ekonomis. Kegiatan pengawasan juga merupakan bagian atau salah satu tugas yang harus dilakukan dalam suatu institusi yang merupakan salah satu kerangka kerja untuk memastikan bahwa setiap permasalahan dan penyimpangan yang terjadi sehubungan dengan pengelolaan keuangan negara/daerah dan pencapaian kinerja sudah ditindaklanjuti secara efektif dan memadai. Untuk mewujudkan sistem pengawasan yang optimal maka harus ditetapkan pendekatan terstruktur dan terintegrasi mulai dari tahap perencanaan, pelaksanaan, pelaporan dan tindak

2 Pedoman Umum Pengelolaan Anggaran Pendapatan dan Belanja Daerah. 
lanjut hasil pengawasan oleh semua pihak dan unit kerja yang berkepentingan, seperti Inspektorat Provinsi, unit kerja yang menjadi objek pengawasan dan pengguna informasi hasil pengawasan.

Sistem pengawasan merupakan unsur manajemen pemerintah yang penting dalam rangka mewujudkan tata pemerintahan yang baik. Inspektorat Provinsi sebagai APIP yang melaksanakan fungsi pengawasan intern pemerintah harus mampu merespon secara signifikan berbagai macam permasalahan dan perubahan yang terjadi, baik politik, ekonomi maupun sosial melalui suatu program dan kegiatan yang ditetapkan dalam suatu kebijakan pengawasan yang menyeluruh.

Untuk mewujudkan sistem pengawasan yang optimal maka harus ditetapkan pendekatan terstruktur dan terintegrasi mulai dari tahap perencanaan, pelaksanaan, pelaporan dan tindak lanjut hasil pengawasan oleh semua pihak dan unit kerja yang berkepentingan, seperti Inspektorat Provinsi, unit kerja yang menjadi objek pengawasan dan pengguna informasi hasil pengawasan. Gambaran hasil Pemeriksaan Kinerja pada SKPD Lingkup Pemerintah Provinsi NTT Tahun 2011 sebagaimana tabel dan diagram berikut.

\begin{tabular}{|c|c|c|c|c|c|c|c|c|c|c|}
\hline \multirow[b]{2}{*}{ No } & \multirow[b]{2}{*}{$\begin{array}{l}\text { Obyek } \\
\text { Pemerik- } \\
\text { saan }\end{array}$} & \multicolumn{3}{|c|}{ Tahun 2010} & \multicolumn{3}{|c|}{ Tahun 2011} & \multicolumn{3}{|c|}{ Tahun 2012} \\
\hline & & $\begin{array}{l}\text { Sasa- } \\
\text { ran }\end{array}$ & Adm & $\begin{array}{c}\text { Kerugian/ } \\
\text { Kewajiban Setor } \\
\text { Kepada Negara / } \\
\text { Daerah }\end{array}$ & $\begin{array}{c}\text { Sasa- } \\
\text { ran }\end{array}$ & Adm & $\begin{array}{c}\text { Kerugian/ } \\
\text { Kewajiban } \\
\text { Setor Kepada } \\
\text { Negara / } \\
\text { Daerah }\end{array}$ & $\begin{array}{c}\text { Sasa- } \\
\text { ran }\end{array}$ & Adm & $\begin{array}{c}\text { Kerugian/ } \\
\text { Kewajiban Setor } \\
\text { Kepada Negara } \\
\text { / Daerah }\end{array}$ \\
\hline 1 & $\begin{array}{l}\text { Sekretariat } \\
\text { Daerah }\end{array}$ & 3 & 28 & $136,217,247$ & 3 & 29 & $5,597,000$ & 4 & 17 & 0 \\
\hline 2 & $\begin{array}{l}\text { Dinas dan } \\
\text { UPT }\end{array}$ & 46 & 403 & $1,318,319,493$ & 49 & 343 & $454,349,517$ & 15 & 114 & $291,194,741.21$ \\
\hline 3 & $\begin{array}{l}\text { Lembaga } \\
\text { Teknis dan } \\
\text { RSUD }\end{array}$ & 13 & 100 & $181,312,866$ & 10 & 88 & $165,641,032$ & 12 & 47 & $20,367,555.00$ \\
\hline & & 62 & 531 & $1,635,849,606$ & 62 & 460 & $625,587,549$ & 31 & 178 & $311,562,296.21$ \\
\hline
\end{tabular}

Data Rekapitulasi Hasil Pemeriksaan pada SKPD Lingkup Pemerintah Provinsi NTT Tahun $2010 \mathrm{~s} / \mathrm{d} .2012^{3}$

3 Sumber data: Inspektorat Provinsi usa Tenggara Timur Tahun 2012 dalam Angka. 
Pada tabel terlihat keseluruhan gambaran tentang hasil pengawasan fungsional yang telah dilakukan Inspektorat Provinsi Nusa Tenggara Timur pada SKPD lingkup Pemerintah Provinsi NTT berupa data rekapitulasi hasil pemeriksaan pada SKPD lingkup Pemerintah Provinsi NTT Tahun 20102012. Sejumlah hal pokok tersebut di atas merupakan fakta dan data yang menunjukan bahwa Inspektorat Provinsi NTT telah melaksanakan fungsi pengawasan internal secara optimal. Sebagai dasar alasan atau bukti adanya optimalisasi kinerja Inspektorat Provinsi NTT dilihat pada diagram nomor 1 tentang gambaran tren dan temuan hasil pemeriksaan kinerja SKPD Pemerintah Provinsi NTT berikut ini:

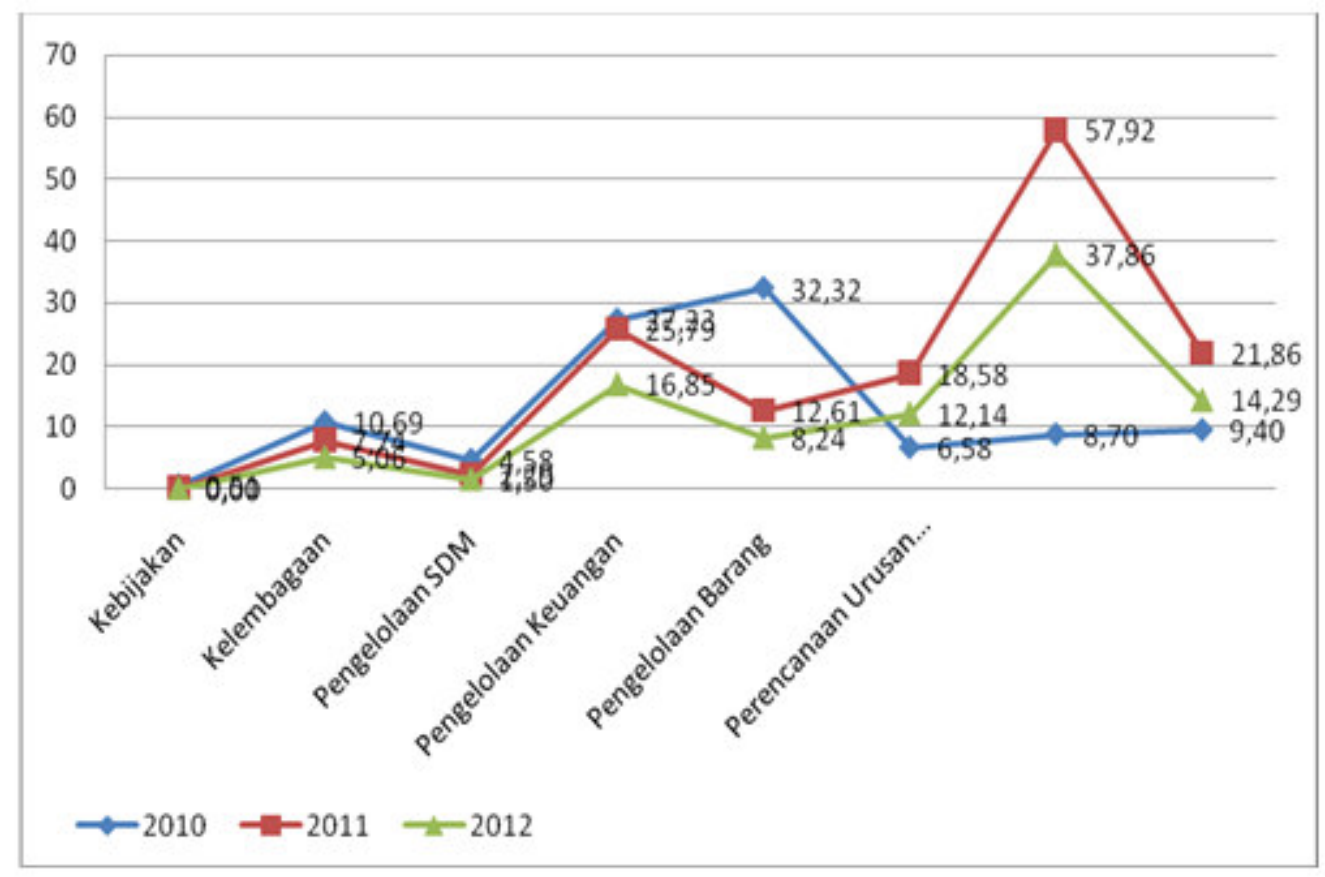

Diagram 2

Gambaran Trend dan Temuan Hasil Pemeriksaan Kinerja SKPD Pemerintah Provinsi NTT Tahun 2012

Diagram tersebut menggambarkan dan mengindikasikan bahwa trend dan temuan hasil pemeriksaan kinerja seluruh SKPD Pemerintah Provinsi Nusa Tenggara Timur terhitung sejak tahun 2010 sampai dengan tahun 2012 tidak stagnan melainkan cukup fluktuatif dalam arti bahwa tren kinerjanya mengalami peningkatan yang cukup optimal dan atau cukup berarti karena mencakup semua aspek yakni aspek kebijakan, kelembagaan, pengelolaan SDM, pengelolaan keuangan, pengelolaan barang, perencanaan urusan pemerintahan, pelaksanaan urusan pemerintahan bahkan sampai pada titik final hasil pelaksanaan urusan pemerintahan. 
Sebagai bukti adanya optimalisasi berikut di bawah ini: kinerja dapat dilihat pada diagram

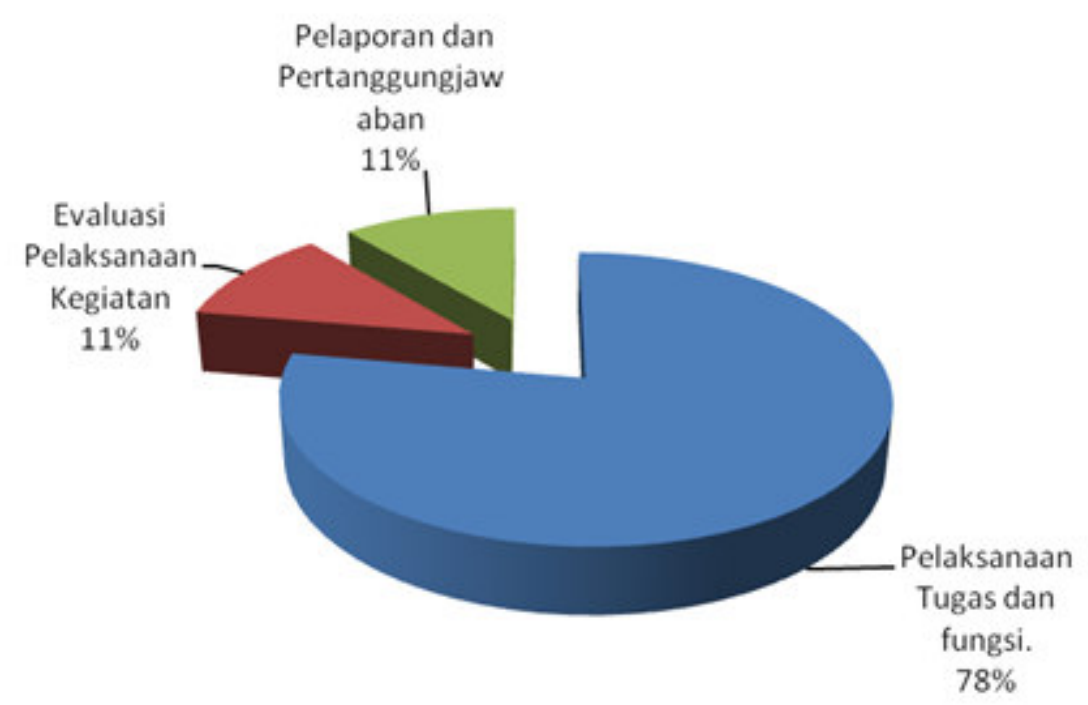

Menyangkut data temuan hasil pemeriksaan aspek pengelolaan keuangan adalah mencakup sejumlah hal penting sebagai berikut:

a. pajak telah dipungut belum setor sebesar 3\%;

b. pajak negara belum dipungut sebesar 6\%;

c. sisa UUDP belum disetor sebesar $7 \%$;

d. kemahalan harga sebesar 3\%;

e. belanja barang fiktif sebesar $6 \%$; f. perjalanan dinas fiktif sebesar $1 \%$;

g. keterlambatan pekerjaan belum dipungut denda sebesar 1\%;

h. kelemahan dalam perencanaan dan penganggaran SKPD sebesar $7 \%$;

i. kelemahan dalam penatausahaan keuangan daerah sebesar $40 \%$;

j. pertanggunjawaban keuangan 26\% (lihat sebesar Diagram nomor 3). 


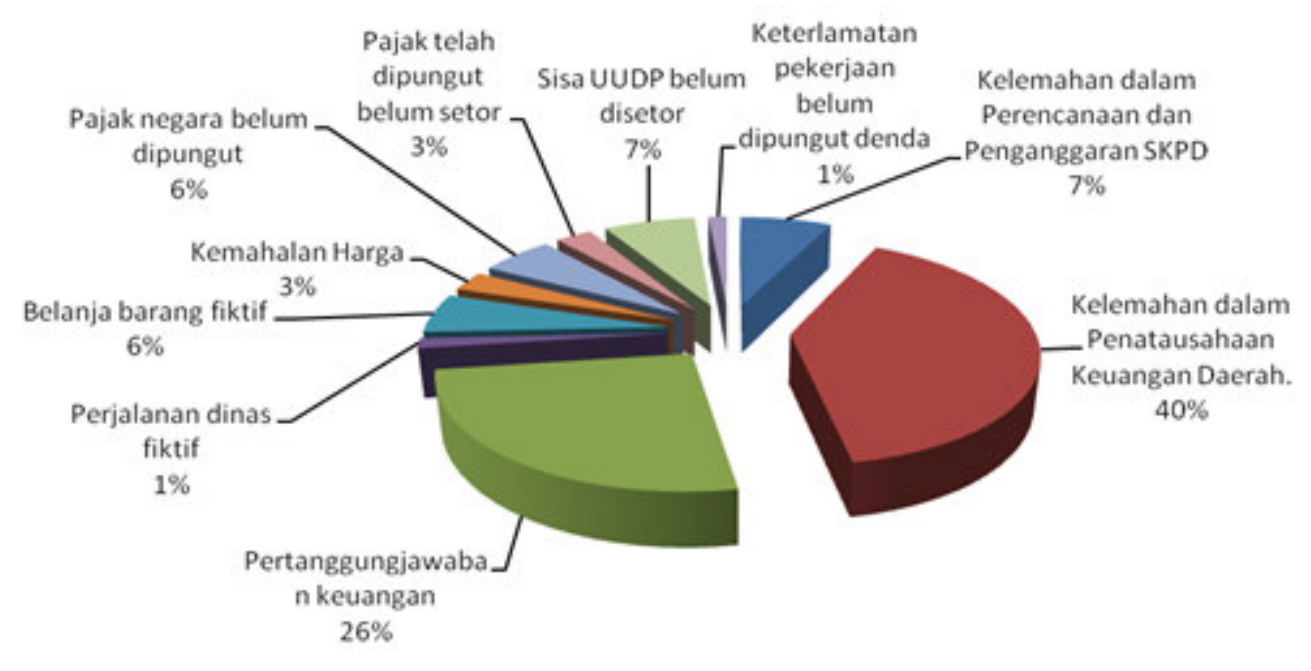

Diagram 3

Data Temuan Hasil Pemeriksaan Aspek Pengelolaan Keuangan pada SKPD Pemerintah Provinsi NTT Tahun 2012

Pada diagram nomor 4 tentang data temuan hasil pemeriksaan aspek pengelolaan barang pada SKPD Pemerintah Provinsi Nusa Tenggara Timur tahun 2012. Dalam diagram tersebut terlihat beberapa hasil temuan sebagai berikut:

a. penatausahaan barang (penyimpanan, inventaris dan pelaporan) sebesar 38\%;

b. proses pemanfaatan barang daerah berupa penyewaan, pinjam pakai dan lain-lain sebesar 24\%;

c. pengamanan dan pemeliharaan barang daerah sebesar 19\%;

d. proses pengadaan barang/jasa sebesar 9\%;

e. perencanaan kebutuhan barang/jasa sebesar 5\%;

f. pemindah tanganan barang daerah sebesar 5\% (lihat Diagram nomor 4). 


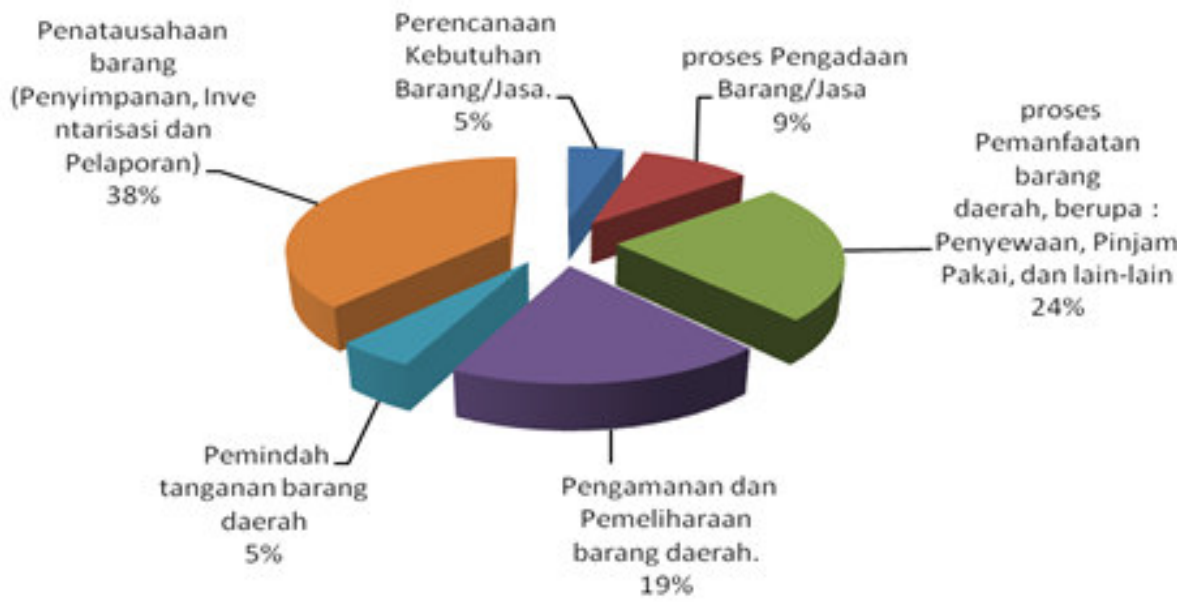

Diagram 4

Data Temuan Hasil Pemeriksaan Aspek Pengelolaan Barang pada SKPD Pemerintah Provinsi NTT Tahun 2012

Merujuk pada keseluruhan hasil analisis baik menyangkut data rekapitulasi pemeriksaan pada SKPD lingkup Pemerintah Provinsi NTT khusus mengenai objek pemeriksaan, jumlah sasaran, administrasi serta kegiatan/ kewajiban setor kepada negara/daerah, maupun menyangkut hasil pemeriksaan aspek kelembagaan, pengelolaan SDM, kelembagaan urusan pemerintahan yang digambarkan dalam bentuk diagram seperti tersebut di atas dapat diketahui dan dipahami secara komprehensif bahwa kinerja pemerintah pada seluruh SKPD Provinsi NTT ratarata belum optimal dalam artian belum efektif dan efisien. Namun pada satu sisi patut dipahami dan diakui pihak pemerintah Provinsi NTT melalui Inspektorat Provinsi NTT mampu melakukan pelaksanaan pengawasan fungsionalnya dalam berbagai aspek secara optimal.

Bagaimana adanya optimalisasi kinerja Inspektorat Provinsi NTT dapat diperlihatkan pada data menyangkut perkembangan temuan kerugian negara/daerah pada SKPD Pemerintah Provinsi NTT sejak tahun 2010-2012. Adanya tren perkembangan temuan kerugian negara/daerah tersebut dapat dijelaskan pada diagram berikut di bawah. 


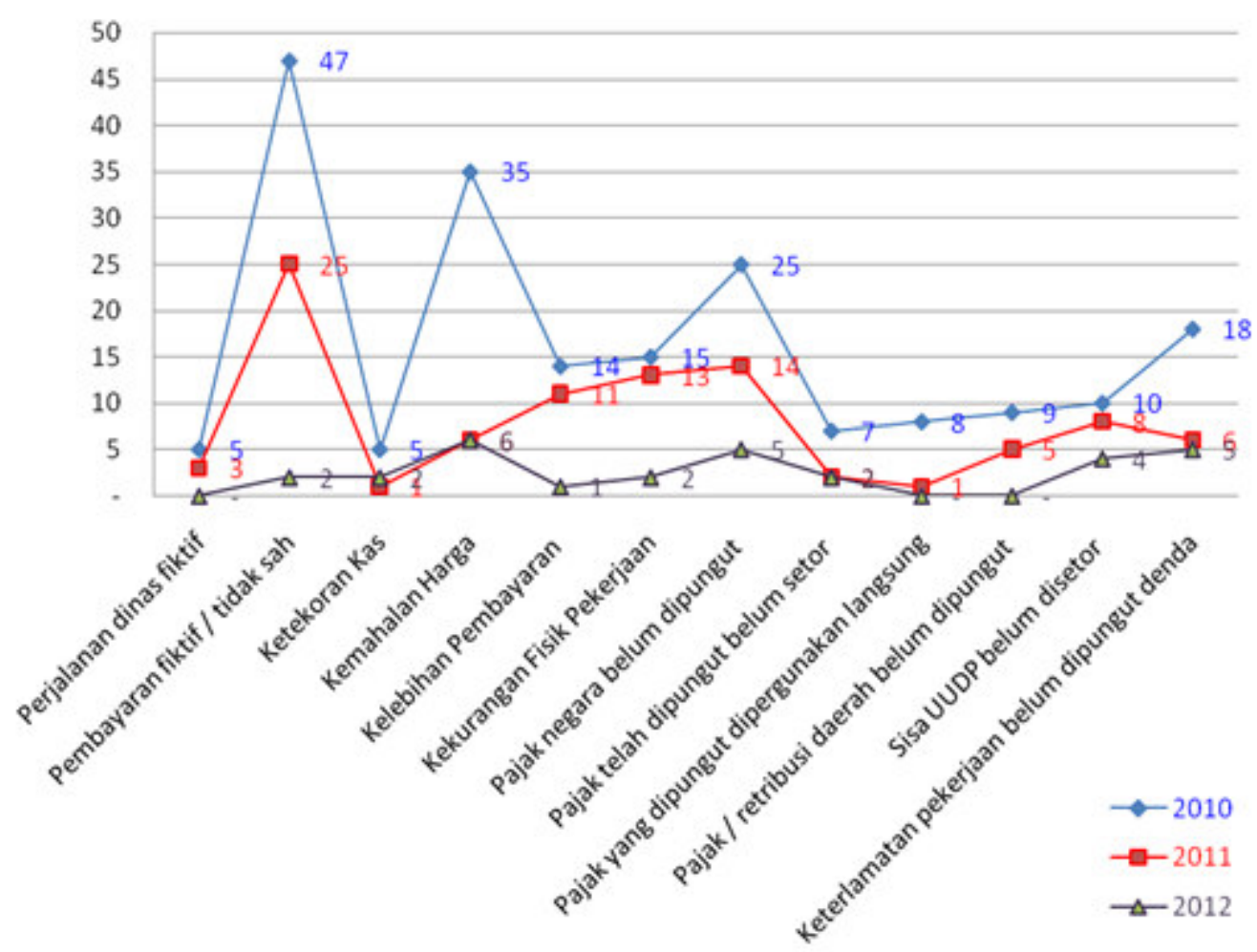

Diagram 5

Perkembangan Temuan Kerugian Negara/Daerah pada SKPD Pemerintah Provinsi NTT Tahun 2010-2012

Sejumlah elemen terkait di atas yang menjadi sumber kerugian/kewajiban setor kepada negara semakin baik dalam arti semakin tertib dan lancar.

Keputusan Menteri Pendayagunaan Aparatur Negara Nomor: Kep/135/ M.Pan/9/2004 mengamanatkan supaya APIP melakukan evaluasi LAKIP pada
SKPD. Sehubungan dengan hal tersebut maka telah dilakukan evaluasi LAKIP pada 43 SKPD Lingkup Provinsi NTT yang hasil evaluasinya disajikan dalam tabel berikut. ${ }^{4}$

\footnotetext{
$4 \quad$ Sumber data: Inspektorat Provinsi Nusa Tenggara Timur Tahun 2012 dalam Angka.
} 


\begin{tabular}{|r|r|r|r|}
\hline \multicolumn{3}{|c|}{ TAHUN } \\
HASIL EVALUASI & 2011 & 2012 & \multicolumn{1}{|c|}{ KETERANGAN } \\
\hline Memuaskan (AA) & 19 & 20 & Meningkat 1 SKPD atau 5,26\% \\
\hline Sangat Baik (A) & 17 & 22 & Meningkat 5 SKPD atau 29,41\% \\
\hline Baik (B) & 4 & 2 & Menurun 2 SKPD atau 50\% \\
\hline Cukup Baik (CC) & 3 & 2 & Menurun 1 SKPD atau 33,33\% \\
\hline Jumlah SKPD & 43 & 46 & Meningkat 3 SKPD atau 6,98\% \\
\hline
\end{tabular}

Berhubung data hasil evaluasi LAKIP untuk tahun 2010 tidak tersedia maka hanya digunakan data hasil evaluasi tahun 2011 dan tahun 2012.

\section{Tindaklanjut Hasil Pengawasan Fungsional di Inspektorat Provinsi NTT}

Untuk meningkatkan kinerja APIP pada umumnya, perlu dilakukan langkah-langkah perbaikan ke depan melalui:

Strategi Pemberdayaan

1. Diterbitkan Undang-Undang Sistem Pengawasan Nasional. UndangUndang Sistem Pengawasan Nasional merupakan kebutuhan yang mendesak untuk segera diterbitkan agar pengawasan terhadap pengelolaan keuangan negara baik yang dilaksanakan oleh APIP maupun Auditor Eksternal dapat berjalan secara efisien dan efektif. Oleh karena itu, seluruh komponen pengawasan internal maupun eksternal harus secara aktif ikut mendorong diterbitkannya Undang-Undang dimaksud.

2. Penerapan Sistem Pengendalian Intern Pemerintah (SPIP). Sampai saat ini Peraturan Pemerintah tentang SPIP dalam proses penerapan, meskipun demikian, guna mendorong peningkatan kinerja pengawasan intern, seyogianya seluruh jaringan APIP memberikan perhatian khusus untuk membantu pimpinan dalam membangun dan mendorong dibangunnya sistem pengendalian intern pada masingmasing unit kerja pemerintah baik di pusat maupun di daerah.

3. Sinergi Pengawasan. Perlu adanya perumusan mekanisme kerjasama pengawasan yang lebih terstruktur dan terencana dengan melibatkan seluruh APIP sehingga ditetapkan prioritas-prioritas kegiatan pengawasan yang akan dilakukan dengan pembagian tugas yang jelas sesuai dengan tugas pokok masingmasing. 
4. Peningkatan Kompetensi dan Profesionalisme SDM. Kompetensi dan profesionalisme merupakan faktor penting yang harus dipenuhi dalam rangka peningkatan kualitas hasil pengawasan. Oleh karena itu, perlu adanya perbaikan sistem rekruitmen dan pengembangan SDM secara terus menerus secara berkesinambungan, guna merespon perubahan kebijakan dalam pengelolaan keuangan negara dan penyelenggaraan pemerintahan pada umumnya, serta perkembangan teknologi yang terus berkembang.

5. Peningkatan Pemenfaatan Hasil Pengawasan sebagai Umpan Balik untuk Pimpinan dalam Perumusan Kebijaksanaan.

Perkembangan Penyelesaian Tindak Lanjut Hasil Pemeriksaan

Pasal 19 Peraturan Menteri Dalam Negeri Nomor 23 Tahun 2007 tentang Tata Cara Pengawasan Penyelenggaraan Pemerintahan Daerah mengamanatkan Inspektorat Provinsi NTT untuk melaksanakan pemantauan dan pemutakhiran penyelesaian tindak lanjut oleh Pemerintah Daerah atas Laporan Hasil Pemeriksaan BPK RI maupun APIP. Selama ini penanganan tindak lanjut hasil pengawasan umumnya difokuskan kepada temuan keuangan sehingga temuan yang terkait dengan kegiatan teknis dan administrasi kurang mendapat penekanan.

Jenis temuan teknis dan administratif tidak dapat diabaikan begitu saja karena kedua jenis temuan tersebut dapat menjadi penyebab terjadinya kerugian negara. Mengacu pada Instruksi Presiden Nomor 15 Tahun 1983 tentang Pedoman Pengawasan, bahwa temuan pengawasan fungsional dapat berupa temuan administratif.

\section{PENUTUP}

Berdasarkan hasil penelitian dan pembahasan mengenai pelaksanaan pengawasan fungsional dalam rangka menuju optimalisasi kerja, dapat disimpulkan hal-hal sebagai berikut. Pertama, Inspektorat Provinsi NTT sebagai sub-sistem pemerintahan mempunyai andil besar dalam terselenggaranya kepemerintahan yang baik dan bebas dari praktik Korupsi, Kolusi dan Nepotisme (Good Governance and Clean Governance).

Kedua, Inspektorat Provinsi NTT sebagai aparat pengawasan fungsional dalam melaksanakan fungsi pengawasan internal pemerintah telah mampu merespon secara signifikan berbagai macam permasalahan dan perubahan yang terjadi, baik politik, ekonomi maupun sosial melalui suatu program dan kegiatan yang ditetapkan dalam suatu kebijakan pengawasan yang menyeluruh. Ketiga, tindak lanjut hasil pengawasan fungsional sangat diperlukan dalam rangka memperbaiki manajemen pemerintah antara lain aspek ketatalaksanaan dan SDM Aparatur, aspek kelembagaan serta dasar penilaian kinerja pimpinan unit kerja, agar suatu temuan yang sama tidak terulang kembali. 
Daftar Bacaan

Manullang, M., Dasar-dasar Manajemen

(Ghalia Indonesia 1982). 